\title{
Glutamina: Aspectos Bioquímicos, \\ Metabólicos, Moleculares e Suplementação
}

Glutamine: Biochemical, Metabolic, Molecular Aspects and Supplementation

Vinicius Fernandes Cruzat

Éder Ricardo Petry

Julio Tirapegui

Departamento de Alimentos e Nutrição Experimental, Faculdade de Ciências Farmacêuticas,

Universidade de São Paulo.

\section{Endereço para correspondência:}

Prof. Dr. Julio Tirapegui

Av. Prof. Lineu Prestes, 580, Bloco 14

São Paulo, SP.

E-mail: tirapegu@usp.br

Submetido em: 21/07/2008

Versão final recebida em: 10/04/2009

Aceito em: 15/04/2009

\begin{abstract}
RESUMO
A glutamina é o aminoácido livre mais abundante no plasma e no tecido muscular. Nutricionalmente é classificada como um aminoácido não essencial, uma vez que pode ser sintetizada pelo organismo a partir de outros aminoácidos. A glutamina está envolvida em diferentes funções, tais como a proliferação e desenvolvimento de células, o balanço acidobásico, o transporte da amônia entre os tecidos, a doação de esqueletos de carbono para a gliconeogênese, a participação no sistema antioxidante e outras. Por meio de técnicas de biologia molecular, estudos demonstram que a glutamina pode também influenciar diversas vias de sinalização celular, em especial a expressão de proteínas de choque térmico (HSPs). As HSPs contribuem para a manutenção da homeostasia da célula na presença de agentes estressores, tais como as espécies reativas de oxigênio (ERO). Em situações de elevado catabolismo muscular, como após exercícios físicos intensos e prolongados, a concentração de glutamina pode tornar-se reduzida. A menor disponibilidade desse aminoácido pode diminuir a resistência da célula a lesões, levando a processos de apoptose celular. Por essas razões, a suplementação com L-glutamina, tanto na forma livre, quanto como dipeptídeo, tem sido investigada. Alguns aspectos bioquímicos, metabólicos e mecanismos moleculares da glutamina, bem como os efeitos de sua suplementação, são abordados no presente trabalho.
\end{abstract}

Palavras-chave: glutamina, exercício, HSP, suplementação, dipeptídeo.

\begin{abstract}
Glutamine is the most frequent free amino acid in the serum and muscular tissue. Nutritionally, it is classified as a non-essential amino acid, once it can be synthesized by the body from other amino acids. Glutamine is involved in different functions, such as cell proliferation and development, basic acid balance, ammonia transportation between tissues, carbon skeleton donation to the gluconeogenesis, participation in the antioxidant system, among others. Molecular biology techniques show that it may also influence several cell signaling ways, especially the expression of heat shock proteins (HSP). The HSPs contribute to the maintenance of the cellular homeostasis in the presence of stress agents such as oxygen reactive species (ORE). In situations of high cellular catabolism, as after intense and prolonged physical exercises, the glutamine concentration may become reduced. Lower availability of this amino acid may decrease the cell resistance to injuries, leading to cellular apoptosis processes. Therefore, L-glutamine supplementation either in free form or as dipeptide has been investigated. Some biochemical and metabolic aspects, molecular mechanism of glutamine, as well as the effects of its supplementation are approached in the present article.
\end{abstract}

Keywords: glutamine, exercise, HSP, supplementation, dipeptide.

\section{INTRODUÇÃO}

Em 1873, Hlasiwetz e Habermann foram os primeiros a considerar a glutamina como sendo uma molécula com propriedades biologicamente importantes. Posteriormente, novas observações levaram os pesquisadores a pensar que a amônia encontrada em hidrolisados proteicos poderia ser o resultado da liberação de glutamina, bem como de asparagina ${ }^{(1,2)}$. Cerca de 60 anos depois, Krebs, em 1935, demonstrou que células possuem a capacidade de sintetizar ou degradar glutamina ${ }^{(2)}$. Trabalhos com diferentes tipos de células, tais como linfócitos, macrófagos, enterócitos, células HeLa, mostraram que tanto a proliferação celular pode ser aumentada, quanto a manutenção das estruturas e funções celulares pode ser mantida, em meios de cultura contendo glutamina(3).
Em todas as células, a glutamina pode ceder átomos de nitrogênio para a síntese de purinas, pirimidinas e aminoaçúcares ${ }^{(4)}$. Resultados de pesquisas evidenciam a importância da glutamina para um grande número de vias metabólicas e tais mecanismos, dependentes de glutamina, passaram a ser denominados como vias glutaminolíticas. $\mathrm{O}$ desenvolvimento de novas técnicas científicas possibilitou a observação de diversos efeitos e mecanismos moleculares em que a glutamina está envolvida ${ }^{(3)}$. Trabalhos demonstram também efeitos agudos e crônicos da suplementação com glutamina em situações catabólicas, tais como câncer, HIV, dengues, sepse, cirurgias, exercícios físicos intensos, entre outros. A síntese, metabolismo, função e suplementação da glutamina são alguns aspectos apresentados nesta revisão. 


\section{Considerações metabólicas e bioquímicas da glutamina}

A glutamina $\left(\mathrm{C}_{5} \mathrm{H}_{10} \mathrm{~N}_{2} \mathrm{O}_{3}\right)$ é um L- $\alpha$-aminoácido, com peso molecular de aproximadamente $146,15 \mathrm{kda}$ e pode ser sintetizada por todos os tecidos do organismo. Fazem parte de sua composição química nas seguintes quantidades: carbono $(41,09 \%)$, oxigênio $(32,84 \%)$, nitrogênio $(19,17 \%)$ e hidrogênio $(6,90 \%)^{(1,5)}$. É classificada de acordo com seu grupamento R como não carregada, mas é polar, o que significa uma característica mais hidrofílica, sendo facilmente hidrolisada por ácidos ou bases ${ }^{(5)}$. Como o organismo pode sintetizar glutamina, esta é considerada como um aminoácido dispensável ou não essencia|(6).

A classificação da glutamina como um aminoácido não essencial, entretanto, tem sido questionada, pois em situações críticas, tais como cirurgias, traumas e exercícios físicos exaustivos, a síntese de glutamina não supre a demanda exigida pelo organismo ${ }^{(7,8)}$. A glutamina é o aminoácido livre mais abundante no plasma e no tecido muscular, sendo também encontrada em concentrações relativamente elevadas em outros diversos tecidos corporais ${ }^{(9)}$. A proliferação e desenvolvimento de células, em especial do sistema imune, o balanço acidobásico, o transporte da amônia entre os tecidos, a doação de esqueletos de carbono para a gliconeogênese, entre outros, são algumas das funções em que a glutamina está envolvida $a^{(5,10)}$.

Duas enzimas são responsáveis pela síntese de glutamina a partir do glutamato ou por sua degradação, também em glutamato, a saber, a glutamina sintetase e a glutaminase, respectivamente ${ }^{(4,9)}$.

Mediante a catálise de conversão de glutamato em glutamina e da utilização da amônia como fonte de nitrogênio e com consumo de trifosfato de adenosina (ATP), a glutamina sintetase é a enzimachave para a síntese da glutamina e para a regulação do metabolismo celular do nitrogênio. A glutamina sintetase é uma aminotransferase amplamente distribuída entre os organismos vivos, sendo sua atividade fundamental para a manutenção da vida de microrganismos e de animais ${ }^{(1,2)}$. Os fatores que regulam a atividade da glutamina sintetase são diversos, tais como glicocorticoides ${ }^{(8)}$, hormônios tiroidianos ${ }^{(1)}$, hormônio do crescimento e insulina ${ }^{(11)}$. São atribuídas diferentes funções às ações da glutamina sintetase ${ }^{(12)}$. No cérebro, é utilizada como um importante agente na redução da concentração de amônia, com consequente desintoxicação e síntese de glutamina para nova síntese de glutamato( ${ }^{(9)}$. No pulmão e no músculo esquelético, é responsável pela manutenção da concentração de glutamina plasmática, sendo essencial em situações patológicas ou de estresse ${ }^{(13)}$. Nos rins, a glutamina sintetase é imprescindível para o controle do metabolismo do nitrogênio e manutenção do pH no organismo ${ }^{(12)}$.

A glutaminase é a enzima que catalisa a hidrólise de glutamina em glutamato e íon amônio. A hidrólise da glutamina representa o primeiro passo na sua utilização a partir da síntese do glutamato. Outras reações podem ocorrer principalmente na via que permite o consumo de glutamina no ciclo do ácido tricarboxílico ${ }^{(14)}$. A glutaminase está envolvida em diversos processos metabólicos e pode ser encontrada em bactérias, plantas e animais. Em mamíferos, a glutaminase pode ser encontrada sob duas isoformas, uma (menos abundante) no fígado e outra nos demais tecidos, tais como rins, cérebro, leucócitos e trato gastrintestinal. Contudo, a sua forma mais ativa apresenta-se principalmente nas mitocôndrias ${ }^{(12)}$.

Indivíduos pesando aproximadamente $70 \mathrm{~kg}$ apresentam cerca de 70-80g de glutamina, distribuída por diversos tecidos corporais. No sangue, a concentração de glutamina é em torno de $500-700 \mu \mathrm{mol} / \mathrm{L}^{(15)}$. Tanto a concentração tecidual quanto a concentração sanguínea de glutamina podem ser influenciadas pela atividade da glutamina sintetase ou da glutaminase ${ }^{(16)}$. Alguns tipos de células, tais como células do sistema imune, rins e intestino, apresentam elevada atividade de glutaminase, sendo assim considerados tecidos consumidores de glutamina ${ }^{(16)}$. Por outro lado, os músculos esqueléticos, os pulmões, o fígado, o cérebro e, possivelmente, o tecido adiposo apresentam elevada atividade da enzima glutamina sintetase, sendo assim considerados tecidos sintetizadores de glutamina ${ }^{(4,17)}$.

Quantitativamente, o principal tecido de síntese, estoque e liberação de glutamina é o tecido muscular esquelético ${ }^{(16)}$. A taxa de síntese de glutamina no músculo esquelético humano é de aproximadamente $50 \mathrm{mmol} / \mathrm{h}$, sendo maior do que qualquer outro aminoácido ${ }^{(4)}$. A elevada capacidade de síntese e liberação de glutamina, principalmente em situações em que há aumento na sua demanda por outros órgãos e tecidos, confere ao músculo esquelético um papel metabólico essencial na regulação da glutaminemia. Eventos cirúrgicos, queimaduras, HIV, câncer e exercícios físicos intensos e prolongados são algumas situações em que se observa que o consumo de glutamina excede a capacidade de síntese corporal|(18)

A predominância do tipo de fibra muscular pode influenciar a síntese de glutamina. Fibras do tipo 1 ou oxidativas podem apresentar cerca de três vezes mais estoques de glutamina em comparação com fibras do tipo 2 ou glicolíticas ${ }^{(9)}$. Essa diferença está relacionada com a maior atividade da glutamina sintetase e a maior disponibilidade de ATP para a síntese de glutamina em fibras oxidativas ${ }^{(12)}$. Dependendo do músculo estudado, quando a síntese de novo da glutamina é inibida, os estoques intramusculares podem ser depletados em aproximadamente sete horas ${ }^{(14)}$.

A síntese da glutamina no músculo esquelético, durante o estado pós- absortivo, ocorre por meio da captação de glutamato, a partir da circulação sanguínea. O glutamato é responsável por 40\% da síntese de glutamina ${ }^{(4)}$. O catabolismo proteico leva à produção de glutamina de forma direta e também à síntese de aminoácidos de cadeia ramificada (ACR), glutamato, aspartato e asparagina ${ }^{(14,19)}$. Os esqueletos de carbono desses aminoácidos são utilizados para a síntese de novo de glutamina ${ }^{(20)}$.

Estudos em ratos demonstram que os ACR são transaminados, quase que exclusivamente, com $\alpha$-cetoglutarato para formar glutamato, que pode fornecer seu grupo amino para formar piruvato, gerando alanina, ou incorporar amônia livre, dando origem à glutamina ${ }^{(20)}$ (figura 1). Entretanto, os ACR não são completamente metabolizados, porque a

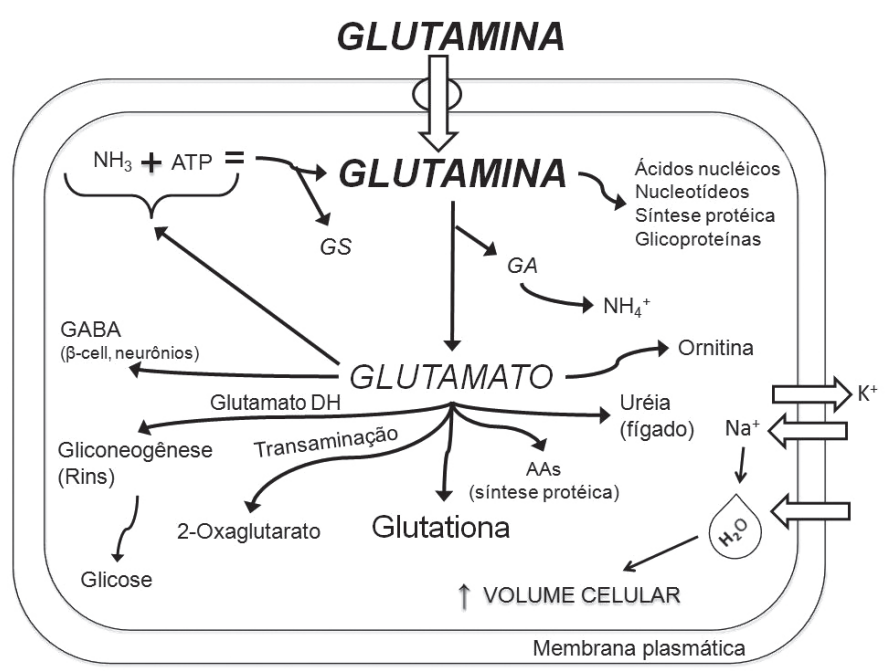

Figura 1. Destinos e funções da glutamina. A partir da glutamina, o glutamato é sintetizado por meio da ação da enzima glutaminase (GA). O glutamato pode ser convertido no aminoácido $\gamma$-amino butirico (GABA), 2-oxaglutarato, glicose, ornitina, ureia, síntese de outros aminoácidos (AAs) ou glutationa. Quando associado a amônia $\left(\mathrm{NH}_{3}\right)$ e trifosfato de adenosina (ATP), sob a ação da enzima glutamina sintetase (GS), o glutamato converte-se novamente em glutamina. Outras abreviaturas: $\mathrm{NH}_{4}^{+}=$íon amônio, $\mathrm{Na}^{+}=$sódio, $\mathrm{K}^{+}=$potássio. Modificado de Newsholme et al. (2003). 
enzima-chave de controle da sua taxa de oxidação, a 2-oxoisovalerato desidrogenase, apresenta-se quase totalmente na forma inativa no músculo esquelético. Consequentemente, no tecido muscular, os ACR captados inicialmente são utilizados como fornecedores de nitrogênio para a formação de glutamina e alanina(21).

Hormônios como a insulina e os fatores de crescimento semelhantes à insulina (IGFs) estimulam o transporte de glutamina para o meio intracelular ${ }^{(18)}$, ao passo que glicocorticoides estimulam a liberação de glutamina para o meio extracelular ${ }^{(5,22)}$. Considerando-se que o gradiente transmembrana através da célula muscular é elevado para a glutamina, sua difusão livre através da membrana celular é restrita(23). Dessa forma, a glutamina necessita ser transportada de forma ativa para o interior das células, por meio de um sistema dependente de sódio $\left(\mathrm{Na}^{+}\right)$, que resulta em gasto de ATP(22,24). Dentre todos os 20 aminoácidos, o transporte de glutamina através da membrana da célula muscular é o mais veloz ${ }^{(10)}$.

A glutamina, ao ser transportada para dentro da célula, promove, concomitantemente, a absorção de água e a liberação de potássio $\left(\mathrm{K}^{+}\right)$, fato que aumenta o estado de hidratação e influencia o volume celular (figura 1) $)^{(17,23,25)}$. Embora ainda controverso, o aumento no volume celular pode estimular a síntese proteica, o que é considerado como um sinal anabólico ${ }^{(21,24,25)}$.

\section{Aspectos moleculares de ação da glutamina}

Estudos têm demonstrado que a glutamina pode influenciar uma variedade de funções e vias de sinalização celular ${ }^{(3)}$. A modulação da expressão de genes relacionados com a síntese e degradação de proteínas, a proliferação celular e a ativação de vias envolvidas com a apoptose celular estão entre os papéis exercidos pela glutamina mais estudados ${ }^{(4,5,26,27)}$.

A glutamina pode modular a ativação de proteínas de estresse ou choque térmico (heat schock proteins - HSPs), que estão relacionadas com a resposta antiapoptótica celular(28). A ativação dessas proteínas corresponde a uma das principais vias de sinalização que contribuem para o aumento da capacidade da célula de sobreviver a alterações na sua homeostasia em decorrência da exposição a agentes estressores, como radiação ultravioleta (UV), calor, agentes infecciosos e espécies reativas de oxigênio (ERO) ${ }^{(28)}$.

As HSPs são famílias de polipeptídios agrupadas de acordo com seu peso molecular, cujo principal fator indutor de sua expressão é o acúmulo de proteínas desnaturadas no meio intracelular ${ }^{(28)}$. Durante o ciclo celular, as HSPs são encontradas em pequenas concentrações e em diferentes compartimentos dentro das células. Quando uma célula é exposta a algum tipo de estresse, são desencadeadas respostas intracelulares, com o objetivo de proteger a célula de uma possível lesão. Essas respostas têm início com a redução transitória da síntese de proteínas consideradas não vitais, seguida por um aumento na transcrição, tradução e expressão de genes específicos que levam ao aumento da concentração das HSPs ${ }^{(29)}$. Elas colaboram no reparo de estruturas na molécula proteica e na identificação e remodelamento de proteínas danificadas durante períodos de estresse. Além disso, as HSPs auxiliam a síntese de novas proteínas, conservando e mantendo sua forma estrutural ${ }^{(30)}$. As HSPs são consideradas essenciais no processo de recuperação celular. Evidências experimentais indicam que o aumento da disponibilidade de glutamina às células pode aumentar a expressão das HSPs, o que mantém a capacidade da célula em resistir a lesões ${ }^{(31)}$.

Em um estudo realizado por Wischmeyer et al. ${ }^{(32)}$ observa-se que, quando adicionada em meio de cultura (2 a $10 \mathrm{mmol} / \mathrm{L}$ ), a glutamina foi eficaz no aumento da proteção de células do epitélio intestinal (enterócitos) de ratos submetidos a lesões do tipo oxidativo. Nesse estudo foi observado aumento na concentração tanto do RNA mensageiro (RNAm) quanto da expressão da HSP de 72kDa (HSP72). Outros estudos confirmam o papel exercido pela glutamina na expressão das HSPs, em especial da HSP de 70kDa (HSP-70) e HSP$72^{(27,33)}$. Outrossim, o efeito da glutamina no aumento da expressão das HSPs ocorre de maneira dose-dependente, pois maiores concentrações são necessárias de acordo com a intensidade do processo, fato que provavelmente está relacionado com a necessidade da célula de aumentar sua proteção e, consequentemente, sobreviver em condições de estresse ${ }^{(27)}$.

Wischmeyer et al. ${ }^{(34,35)}$ observaram aumento na expressão de outras HSPs, tais como a HSP de 25kDa (HSP-25) e a de 27kDa (HSP-27). Tais resultados foram verificados em diversos tecidos de animais que não foram expostos a qualquer tipo de estresse e que receberam glutamina (0,15 a 0,75g/kg de peso corporal) de forma parenteral. A administração de glutamina, principalmente na quantidade de $0,75 \mathrm{~g} / \mathrm{Kg}$ de peso corporal, reduziu a mortalidade de ratos expostos à endotoxemia, observando-se aumento na expressão da HSP-27 e HSP-72.

Resultados de estudos, tanto in vitro quanto in vivo, evidenciam a importância fisiológica da glutamina na expressão das HSPs, principalmente no aumento da proteção da integridade celular. Os mecanismos intracelulares e extracelulares que modulam a expressão dessas proteínas, contudo, ainda necessitam ser mais investigados ${ }^{(30)}$. A expressão do fator transcricional de choque térmico-1 (HSF-1) corresponde a um dos mecanismos reguladores da capacidade da célula em ativar as HSPs em resposta a vários tipos de estresse 28,36$)$.

O HSF-1 é um fator transcricional encontrado na sua forma inativa, ou seja, não ligado ao DNA. A ativação do HSF-1 se dá por meio de uma variedade de estímulos de estresse que desencadeiam a fosforilação de monômeros latentes inativos desse fator transcricional, encontrados no citoplasma da célula. Quando fosforilados, esses monômeros se combinam, convertendo-se em um oligômero homotrímero ${ }^{(37)}$. Os homotrímeros do HSF-1, ao ser ativados, se translocam para o núcleo da célula e se ligam a locais específicos da região promotora dos genes das HSPs, denominados elementos de choque térmico (HSEs) ${ }^{(36)}$. Esse mecanismo permite que sinais específicos iniciem o processo de síntese, transcrição e tradução do RNAm das HSPs (figura 2) $)^{(37)}$.

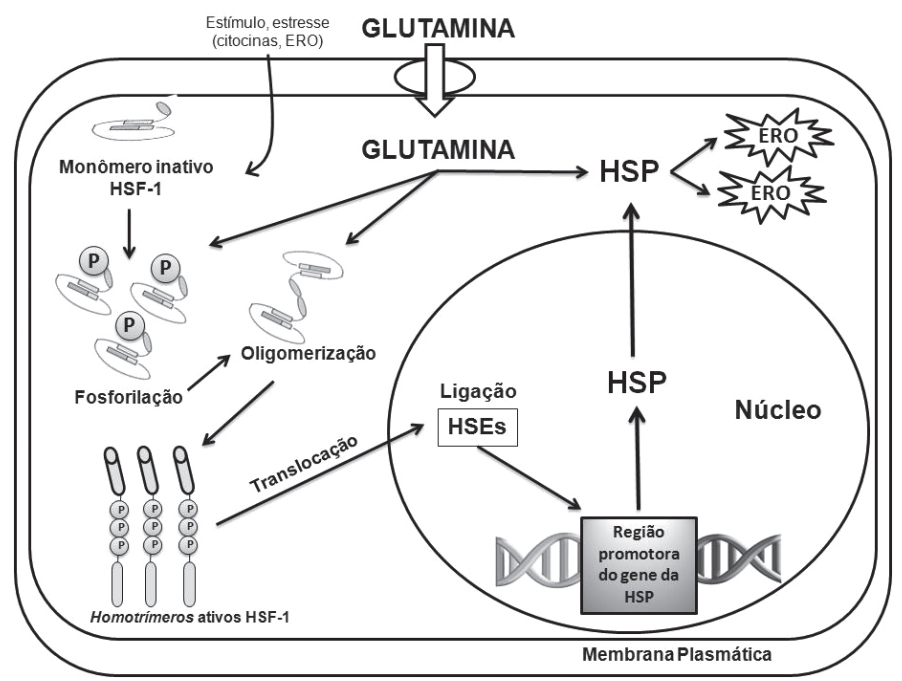

Figura 2. Esquema representativo do mecanismo de transcrição, tradução e expressão de HSPs, por meio da ativação do HSF-1 e influência da glutamina nesse mecanismo. Abreviaturas: HSP = proteína de choque térmico, HSF-1 = fator de choque térmico-1. HSES = elementos de choque térmico, ERO = espécies reativas de oxigênio. 
Morrison et al. ${ }^{(38)}$ verificaram que a glutamina pode modular o processo de tradução e expressão tanto do HSF-1 quanto das HSPs. Os autores observaram que o aumento da concentração de glutamina estimulou tanto o número de ligações dos homotrímeros do HSF1 aos HSEs, quanto a ligação desses HSEs à região promotora dos genes das HSPs. Peng et al.(.39) observaram que, quando adicionada a células fibrobláticas embrionárias de rato, a glutamina pode induzir aumento na expressão do HSF-1, o que contribui para a integridade da membrana celular.

Evidências experimentais demonstram que a maior parte das funções exercidas pelo aumento da expressão das HSPs está associada ao fato de essas proteínas apresentarem atividade ATP-dependente, o que Ihes possibilita agir como proteínas chaperonas em nível molecular, atuando na proteção contra diversos processos de apoptose celular ${ }^{(30)}$. O elemento fundamental dessa proteção é a ação inibitória realizada pelas HSPs, por meio de sua ligação à rede de proteases essenciais à apoptose celular, como a caspase-9 e o fator apoptótico ativador de proteases-1 (APAF-1)(28). Outro mecanismo envolvido está relacionado com a ação isolada de algumas HSPs, principalmente a HSP-27, HSP-70 e HSP-72, na redução da agregação de proteínas nucleares ${ }^{(28)}$.

A inibição de vias de sinalização intracelular, tais como a da proteína quinase ativada por mitógenos (MAPK) e do fator nuclear kappa $\mathrm{B}(\mathrm{NF}-\mathrm{KB})$, também tem sido indicada como mecanismo envolvido na proteção antiapoptótica desempenhada pelas $\mathrm{HSPS}^{(26,40)}$. Tanto a via da MAPK, quanto a do NF-KB, ao ser inibidas, reduzem a ativação de sinais de tradução e expressão de citocinas pró-inflamatórias, tais como a interleucina-1 $\beta$ (IL-1 $\beta$ ) e o fator de necrose tumoral- $\alpha(\text { TNF- } \alpha)^{(26)}$.

De acordo com Wernerman e Hammarqvist ${ }^{(41)}$, os mecanismos de ativação tanto do NF-KB quanto da MAPK são dependentes do estado redox celular, que pode ser alterado de acordo com a concentração intracelular de glutationa (GSH). Por sua vez, a GSH é influenciada pela disponibilidade de glutamina e glutamato intracelu$\operatorname{lar}^{(17,42)}$. Assim, a ativação do NF-אB e da MAPK pode ser modulada pela glutamina ${ }^{(26,42)}$. Em animais submetidos a estado de sepse, a maior disponibilidade de glutamina atenuou a ativação do complexo NF-KB, por meio da inibição da degradação de sua proteína inibido$r a, \mid \kappa B-\alpha$, e inibiu a fosforilação e a ativação da MAPK ${ }^{(26)}$. Em outro estudo, Singleton e Wischmeyer ${ }^{(27)}$ verificaram que a administração de glutamina promoveu aumento de maneira dose-dependente da expressão da HSP-70, inibindo a ativação do NF-KB e das proteínas quinases que compõem a via da MAPK, sobretudo a c-JUN NH$H_{2}$-terminal quinase (JNK).

\section{Suplementações com glutamina}

Estudos nos quais a L-glutamina foi administrada de forma parenteral demonstraram que a maior oferta desse aminoácido às células pode atenuar sua redução no plasma ou no meio intracelular ocorrido após eventos de estresse metabólico ou enfermidades, tais como dengue ${ }^{(43)}$, câncer ${ }^{(44)}$, HIV ${ }^{(45)}$, queimaduras, cirurgias ${ }^{(44,46)}$, entre outros. Nesses estudos, a utilização de glutamina tem sido correlacionada com melhora na recuperação dos pacientes $(2,46,47)$.

Déchelotte et al.(48) verificaram que, no estado pós-absortivo, a suplementação oral com glutamina em indivíduos saudáveis e sedentários promoveu aumento na concentração de glutamina e glutamato plasmáticos. Em atletas no estado de repouso, Castell e Newsholme ${ }^{(49)}$ observaram que a concentração plasmática de glutamina aumentou cerca de 30 minutos após a ingestão oral de uma solução com L-glutamina (100 mg/kg de peso corporal), podendo retornar aos valores basais no decorrer de aproximadamente duas horas.
Em indivíduos fisicamente ativos, Bowtell et al.(50) verificaram o efeito da suplementação oral com L-glutamina sobre a glutaminemia e os estoques de glicogênio muscular, após sessão de exercício intenso de corrida. A suplementação ( $8 \mathrm{~g}$ de glutamina em $330 \mathrm{~mL}$ de água) aumentou a concentração plasmática de glutamina durante o período de recuperação em 46\%, o que permite inferir que uma substancial proporção de glutamina administrada oralmente escapou da utilização por parte das células da mucosa intestinal e da captação pelo rim e fígado.

Uma vez que células do sistema imune necessitam de glutamina para a manutenção de suas funções e o exercício físico induz o aumento da atividade dessas células, a correlação entre glutamina e sistema imune tem sido estudada ${ }^{(2,6)}$. Especula-se que a redução da disponibilidade de glutamina, ocorrida após exercícios intensos e prolongados possa, de alguma forma, estar envolvida no desenvolvimento de doenças, em especial, as infecções do trato respiratório superior $(\text { (TRS) })^{(19)}$. A suplementação com L-glutamina tem sido estudada como alternativa de atenuar ou mesmo de reverter tais eventos induzidos pelo exercício físico (tabela 1) ${ }^{(6,51)}$. Castell et al.(52) investigaram o efeito da suplementação com L-glutamina ( $5 \mathrm{~g}$ em $330 \mathrm{~mL}$ de água) logo após a realização de uma maratona. A concentração de glutamina, alanina e ACR manteve-se diminuída por até uma hora após a realização da maratona, retornando aos valores pré-exercício somente 16 horas mais tarde. Algumas citocinas, tais como a IL-2 e o TNF- $\alpha$, tiveram suas concentrações plasmáticas aumentadas por várias horas após o exercício, 0 que denota um marcante estado inflamatório induzido pelo exercício. A suplementação com L-glutamina, contudo, não alterou nenhum dos parâmetros analisados.

Estudos relacionando glutamina com o volume celular demonstram que o seu transporte para o meio intracelular promove elevação na captação de sódio, alterando o volume da célula $a^{(59,60)}$. O aumento no volume celular pode ser considerado um sinal anabólico, uma vez que altera favoravelmente o turnover proteico, promovendo a síntese proteica e aumentando a disponibilidade de substratos para os diversos sistemas envolvidos no processo de recuperação e reparação tecidual ${ }^{(43,61)}$. Varnier et al. ${ }^{(62)}$ observaram que a administração parenteral de glutamina, após exercício de alta intensidade, promoveu o aumento dos estoques de glicogênio muscular, fato que pôde beneficiar a recuperação da lesão induzida pelo exercício exaustivo.

O aumento do volume celular, contudo, não é o único mecanismo pelo qual a glutamina pode influenciar outros sistemas envolvidos na homeostasia celular, tais como o sistema antioxidante. No meio intracelular, a glutamina pode sofrer hidrólise e elevar a disponibilidade de glutamato, que é essencial para a síntese do principal antioxidante celular, a GSH ${ }^{(17)}$. Indivíduos após ser submetidos a eventos de estresse metabólico, tais como cirurgias na região abdominal, foram suplementados, de forma parenteral, durante três dias com L-glutamina. Os resultados mostraram que a intervenção com L-glutamina atenuou a depleção muscular de GSH, o que beneficiou a recuperação dos pacientes ${ }^{(46)}$. A forma de administração pode influenciar o metabolismo da glutamina, bem como a síntese de GSH. De fato, Valencia et al.(47), quando investigaram os efeitos da suplementação com L-glutamina, porém por via oral, em humanos sedentários, não observaram aumento na concentração de GSH plasmática. Os valores de glutamina e glutamato plasmáticos, contudo, se elevaram em comparação com os do grupo controle do estudo.

A utilização de dipeptídeos de glutamina, tais como a L-alanilL-glutamina por via oral, representa uma alternativa não invasiva de aumentar a disponibilidade de glutamina às células ${ }^{(43,63,64)}$. De fato, a suplementação aguda oral com o dipeptídeo (L-alanil-L-glutamina) 
Tabela 1. Estudos com a suplementação oral de glutamina e sua relação com os sistemas imune e antioxidante.

\begin{tabular}{|c|c|c|c|c|}
\hline Referência & Amostra e exercício & Suplementação & Parâmetros avaliados & Resultados \\
\hline $\begin{array}{l}\text { Castell; Newsholme } \\
\text { (1996) }\end{array}$ & $\begin{array}{l}151 \text { corredores de marato- } \\
\text { nas e ultramaratonas }\end{array}$ & $\begin{array}{l}5 \mathrm{~g} \text { de glutamina em } 330 \mathrm{ml} \text { de água ime- } \\
\text { diatamente após e } 2 \text { h após o exercício }\end{array}$ & Questionários de relatos de ITRS & $\begin{array}{l}\text { Grupo suplementado obteve menor per- } \\
\text { centual de ITRS, se comparado com o grupo } \\
\text { placebo }\end{array}$ \\
\hline Castell et al. (1997) & $\begin{array}{l}18 \text { corredores: Maratona de } \\
\text { Bruxelas }\end{array}$ & $\begin{array}{l}5 \mathrm{~g} \text { de glutamina em } 330 \mathrm{ml} \text { de água } 1 \mathrm{~h} \\
\text { após o exercício }\end{array}$ & $\begin{array}{l}\text { Contagem de células, IL-1 } \alpha, \mathrm{IL}-2, \mathrm{IL}-6 \text {, } \\
\text { glutamina, alanina, BCAA plasmáticos } \\
\text { e norepinefrina }\end{array}$ & Nenhum efeito \\
\hline Rohde et al. (1998) & $\begin{array}{l}16 \text { corredores: Maratona de } \\
\text { Copenhague }\end{array}$ & $\begin{array}{l}\text { 100mg/kg de peso corporal de glutamina } \\
\text { diluída em suco de limão, administrada 0, } \\
\text { 30,60, } 90 \text { min. após o exercício }\end{array}$ & $\begin{array}{l}\text { Linfócitos (CD4, CD8, CD16), neu- } \\
\text { trófilos, resposta proliferativa a PHA, } \\
\text { atividade de células LAK }\end{array}$ & $\begin{array}{l}\text { Nenhum efeito da intervenção, somente } \\
\text { efeito do exercício sobre o sistema imune. } \\
\text { Nenhuma relação entre a redução da gluta- } \\
\text { minemia com a atividade de LAK }\end{array}$ \\
\hline Walsh et al. (2000) & $\begin{array}{l}\text { Sete atletas submetidos a } \\
\text { dois treinos separados, em } \\
\text { intensidade de } 60 \% \mathrm{VO}_{2 \text { máx }}\end{array}$ & $\begin{array}{l}\text { Após } 90 \text { minutos de exercício, 1,2\% (w/v) } \\
\text { de glutamina diluída em } 250 \mathrm{ml} \text { de suco } \\
\text { de limão sem açúcar foi administrada em } \\
\text { intervalos de } 15 \text { min. durante e até } 2 \mathrm{~h} \text { após } \\
\text { o fim da atividade }\end{array}$ & $\begin{array}{l}\text { Cortisol, degranulação e atividade de } \\
\text { neutrófilos }\end{array}$ & $\begin{array}{l}\text { A suplementação atenuou a redução na } \\
\text { concentração de glutamina após o exercício, } \\
\text { mas nenhum efeito sobre a leucocitose e a } \\
\text { degranulação de neutrófilos foi encontrada }\end{array}$ \\
\hline $\begin{array}{l}\text { Krzywkowski et al. } \\
\text { (2001a) }\end{array}$ & $\begin{array}{l}11 \text { atletas submetidos três } \\
\text { treinos separados de } 2 \mathrm{~h} \text { em } \\
\text { cicloergômetro a } 75 \% \text { do } \\
\mathrm{VO}_{2 \text { máx }}\end{array}$ & $\begin{array}{l}\text { Grupo glutamina ( } 3,5 \mathrm{~g} \text { de glutamina em } \\
500 \mathrm{ml} \text { ), grupo proteína ( } 13,7 \mathrm{~g} \text { de proteínas } \\
\text { com caseínas, sendo } 1,23 \mathrm{~g} \text { de glutamina } \\
\text { em } 375 \mathrm{ml} \text { de água) administrados durante } \\
\text { e até } 2 \mathrm{~h} \text { após o exercício }\end{array}$ & Secreção de IgA salivar & Nenhum efeito \\
\hline $\begin{array}{l}\text { Krzywkowski et al. } \\
\text { (2001b) }\end{array}$ & $\begin{array}{l}10 \text { atletas submetidos a dois } \\
\text { treinos separados de } 2 \mathrm{~h} \text { em } \\
\text { cicloergômetro a } 75 \% \text { do } \\
\mathrm{VO}_{2 \text { máx }}\end{array}$ & $\begin{array}{l}\text { 3,5g de glutamina em } 500 \mathrm{ml} \text { de água } \\
\text { administrados: } 60 \text { minutos após início da } \\
\text { atividade e quatro vezes após o término } \\
\text { da mesma com intervalos de } 45 \text { min entre } \\
\text { as doses }\end{array}$ & $\begin{array}{l}\text { Contagem de células, resposta proli- } \\
\text { ferativa a PHA de BMNC e atividade } \\
\text { de células NK }\end{array}$ & Nenhum efeito \\
\hline $\begin{array}{l}\text { Valencia et al. } \\
\text { (2002b) }\end{array}$ & Três indivíduos sedentários & 0,3g/kg/dia por 10 dias & $\begin{array}{l}\text { Concentração de glutamina, gluta- } \\
\text { mato e GSH no plasma durante } 24 \mathrm{~h}\end{array}$ & $\begin{array}{l}\text { Aumentou a concentração de glutamina e } \\
\text { glutamato e reduziu a GSH no plasma }\end{array}$ \\
\hline Hiscock et al. (2003) & $\begin{array}{l}\text { Oito atletas submetidos a } \\
\text { três treinos separados de } \\
2 \mathrm{~h} \text { de em cicloergômetro a } \\
75 \% \text { do } \mathrm{VO}_{2 \text { máx }}\end{array}$ & $\begin{array}{l}\text { 3,5g de glutamina em } 500 \mathrm{ml} \text { de água } \\
\text { administrados: } 60 \text { min após início da ati- } \\
\text { vidade e quatro vezes após o término da } \\
\text { mesma com intervalos de } 45 \text { min entre } \\
\text { as doses }\end{array}$ & $\begin{array}{l}\text { Concentração de IL-6 e glutamina } \\
\text { plasmática }\end{array}$ & $\begin{array}{l}\text { Concentração de IL-6 aumentou } 11 \text { vezes no } \\
\text { grupo placebo, } 14 \text { vezes no grupo proteína e } \\
18 \text { vezes no grupo glutamina. A redução na } \\
\text { concentração de glutamina foi atenuada no } \\
\text { grupo glutamina e proteína }\end{array}$ \\
\hline
\end{tabular}

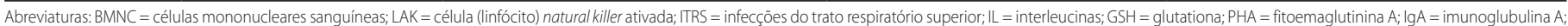
$B C A A=$ aminoácidos de cadeia ramificada

em ratos sedentários foi mais eficiente em promover o aumento da concentração plasmática de glutamina (após 30 minutos da intervenção nutricional) do que quando o aminoácido foi ministrado na forma livre ${ }^{(63)}$.

Em um estudo foi avaliado o efeito da suplementação crônica oral com L-glutamina na forma livre ou como dipeptídeo sobre as concentrações plasmática, muscular e hepática de glutamina em ratos sedentários ${ }^{(65)}$. Os resultados demonstraram que a suplementação crônica com L-glutamina livre ou dipeptídeo não alterou a glutaminemia; o grupo suplementado com o dipeptídeo, contudo, apresentou maior concentração de glutamina muscular e hepática.

Em animais exercitados e submetidos a teste de exaustão, Rogero et al. ${ }^{(64)}$ observaram que a suplementação crônica com o dipeptídeo promoveu maior concentração de glutamina nos músculos sóleo e gastrocnêmio imediatamente após o teste de exaustão em relação aos grupos controle e suplementado com L-glutamina livre. Esses estudos in vivo demonstraram que a utilização de glutamina na forma de dipeptídeo pode vir a ser uma interessante alternativa de intervenção nutricional para o fornecimento de glutamina por via oral ao organismo, tanto em situações de repouso quanto em situações de estresse metabólico, como em exercícios físicos intensos e prolongados.

\section{CONCLUSÃO}

A glutamina está envolvida na síntese de ácidos nucleicos, nucleotídeos, proteínas entre outros. Quando catalisada pela enzima glutaminase, a glutamina dissocia-se em íon amônio e glutamato. Por meio do glutamato, pode ocorrer a síntese de outros aminoácidos e de antioxidantes como a GSH, principal antioxidante celular não enzimático. A realização de exercícios físicos intensos e prolongados pode reduzir a disponibilidade de glutamina às células, o que influencia tanto a concentração de GSH quanto a expressão de HSPs. Uma das principais vias da síntese de HSPs ocorre por meio da ativação do HSF-1. Estudos demonstram que a glutamina pode modular a ativação do HSF-1, aumentando a expressão de HSPs, o que resulta em maior proteção da célula e menor ativação de redes de sinalização celular pró-apoptóticas. A suplementação com o dipeptídeo L-alanilL-glutamina pode representar uma eficiente alternativa de aumentar a disponibilidade de glutamina ao organismo.

\section{AGRADECIMENTOS}

Agradecemos ao apoio da Capes pelas bolsas de estudo concedidas e à Fundação de Amparo à Pesquisa do Estado de São Paulo Fapesp (processo nº 05/59003-2 e 07/58222-8) pelo apoio financeiro. 
1. Curi R. Glutamina: metabolismo e aplicações clínicas e no esporte. Rio de Janeiro: Sprint, 2000. 261 p. 2. Hiscock N, Pedersen BK. Exercise-induced immunodepression - plasma glutamine is not the link. J Appl Physiol. 2002;93:813-22.

3. Curi R, Lagranha CJ, Doi SQ, Sellitti DF, Procopio J, Pithon-Curi TC, Corless M, Newsholme P. Molecular mechanisms of glutamine action. J Cell Physiol. 2005;204:392-401.

4. Newsholme P, Procopio J, Lima MMR, Pithon-Curi TC, Curi R. Glutamine and glutamate - their central role in cell metabolism and function. Cell Biochem Funct. 2003;21:1-9.

5. Rogero MM, Tirapegui JO. Considerações nutricionais e bioquímicas da suplementação de glutamina em atletas: controvérsias e aspectos atuais. J Metab Nutr. 2003;7:106-17.

6. Moreira A, Kekkonen RA, Delgado L, Fonseca J, Korpela R, Haahtela T. Nutritional modulation of exercise-induced immunodepression in athletes: a systematic review and meta-analysis. Eur J Clin Nutr. 2007;61:443-60

7. Wray CJ, Mammen JMV, Hasselgren P. Catabolic response to stress and potential benefits of nutrition support. Nutrition. 2002;18:971-7.

8. Santos RVT, Caperuto EC, Costa Rosa LFBP. Effects of acute exhaustive physical exercise upon glutamine metabolism of lymphocytes from trained rats. Life Sci. 2007:80:573-8.

9. Rowbottom DG, Keast D, Morton AR. The emerging role of glutamine as an indicator of exercise stress and overtraining. Sports Med. 1996;21:80-97.

10. Newsholme P, Lima MMR, Procopio J, Pithon-Curi TC, Doi SQ, Bazotte RB, et al. Glutamine and glutamate as vital metabolites. Braz J Med Biol Res. 2003;36:153-63.

11. Ardawi, MSM. Glutamine-synthesizing activity in lungs of fed, starved, acidotic, diabetic, injured and septic rats. Biochem J. 1990;270:829-32.

12. Labow BI, Souba WW, Abcouwer SF. Mechanisms governing the expression of the enzymes of glutamine metabolism - glutaminase and glutamine synthetase. J Nutr. 2001;131:24675-745.

13. Pinel C, Coxam V, Mignon M, Taillandier D, Cubizolles C, Lebecquea P, et al. Alterations in glutamine synthetase activity in rat skeletal muscle are associated with advanced age. Nutrition. 2006;22:778-85.

14. Rennie MJ, Bowtell JL, Bruce M, Khogali SEO. Interaction between glutamine availability and metabolism of glycogen, tricarboxylic acid cycle intermediates and glutathione. J Nutr. 2001;131:24885-90S.

15. D'Souza R, Tuck JP. Glutamine supplements in the critically ill. J Royal Soc Med. 2004;97:425-7.

16. Van De Poll MCG, Soeters PB, Deutz NEP, Fearon KCH, Dejong CHC. Renal metabolism of amino acids: its role in interorgan amino acid exchange. Am J Clin Nutr. 2004;79:185-97.

17. Cruzat VF, Rogero MM, Borges MC, Tirapegui J. Aspectos atuais sobre estresse oxidativo, exercícios físicos e suplementação. Rev Bras Med Esporte. 2007;13:336-42.

18. Parry-Billings M, Leighton B, Dimitriadis G, Vasconcelos PRL, Newsholme EA. Skeletal muscle glutamine metabolism during sepsis in the rat. Int J Biochem. 1989;21:419-23.

19. Rogero MM, Tirapegui JO. Aspectos atuais sobre glutamina, atividade física e sistema imune. Rev Bras Cie Farm. 2000;36:202-12.

20. Hall GV, Wagenmakers AJM. Effect of carbohydrate supplementation on plasma glutamine during prolonged exercise and recovery. Int J Sports Med. 1998;19:82-6.

21. Meijer AJ. Amino acids as regulators and components of nonproteinogenic pathway. J Nutr. 2003;133:20575-62S

22. Windmueller HG. Glutamine utilization by the small intestine. Adv Enzymol Relat Areas Mol Biol. 1982;53:201-37.

23. Rogero MM, Tirapegui JO. Aspectos nutricionais sobre glutamina e atividade física. Nutrire. 2003;25:87-112.

24. Häussinger D, Lang F, GerokW. Regulation of cell function by the cellular hydration state. Am J Physiol. 1994;267:E343-55

25. Varnier M, Leese GP, Thompson J, Rennie MJ. Stimulatory effect of glutamine on glycogen accumulation in human skeletal muscle. Am J Physiol Endocrinol Metab. 1995;269:E309-15.

26. Singleton KD, Beckey VE, Wischmeyer PE. Glutamine prevents activation of NF-kB and stress kinase pathways, attenuates inflammatory cytokine release, and prevents acute respiratory distress syndrome (ARDS) following sepsis. Schock. 2005;24:583-9.

27. Singleton KD, Wischmeyer PE. Glutamine protection against sepsis and lung injury is dependent on heat shock protein 70 expression. Am J Physiol Regul Integr Comp Physiol. 2007;292:1839-45.

28. Gabai VL, Sherman MY. Interplay between molecular chaperones and signaling pathways in survival of heat shock. J Appl Physiol. 2002;92:1743-8.

29. Wischmeyer PE. Glutamine and heat shock protein expression. Nutrition. 2002;18:225-8.

30. Burg MB, Ferraris JD, Dmitrieva NI. Cellular response to hyperosmotic stresses. Physiol Res. 2007;87:1441-74.

31. Sandres MM, Kon C. Glutamine is a powerfull effector of heat shock protein expression in drosophila Kc cells. Am J Cell Physiol. 1991;146:180-90.

32. Wischmeyer PE, Musch MW, Madonna MB, Thisted R, Chang EB. Glutamine protects intestinal cells: role of inducible HSP 70. Am J Physiol Gastrointest Liver Physiol. 1997;272:879-84

33. Wischmeyer PE, Riehm J, Singleton KD, Ren H, Musch MM, Kahana M, et al. Glutamine attenuates tumor necrosis factor-release and enhances heat shock protein 72 in human peripheral blood mononuclear cells. Nutrition. 2003;19:1-6.

34. Wischemyer PE, Kahana M, Wolfson R, Ren H, Musch MM, Chang EB. Glutamine reduces cytokine release, organ damage, and mortality in a rat model of endotoxemia. Shock. 2001;16:398-402.

35. Wischmeyer PE, Kahana M, Wolfson R, Ren H, Musch MM, Chang EB. Glutamine induces heat shock protein and protects against endotoxin shock in rat. J Appl Physiol. 2001;90:2403-10.
36. Atalay M, Oksala NKJ, Laaksonen DE, Khanna S, Nakao C, Lappalainen J, et al. Exercise training modulate heat shock protein response in diabetes. J Appl Physiol. 2004;97:605-11.

37. Ahn SG, Thiele D. Redox regulation of mammalian heat shock 1 is essential for HSP gene activation and protection from stress. Genes Dev. 2003;17:516-28.

38. Morrison AL, Dinges M, Singleton KD, Odims K, Wong HR, Wischmeyer PE. Glutamine's protection against cellular injury is dependent on heat shock factor-1. Am J Physiol Cell Physiol. 2006;290:C1625-32.

39. Peng ZY, Serkova NJ, Kominsky DJ, Brown JL, Wischemeyer PE. Glutamine-mediated attenuation of cellular metabolic dysfunction and cell death after injury is dependent on heat shock factor-1 expression. J Parent Ent Nutr. 2006;30:373-9.

40. Yoo CG, Lee S, Lee CT. Anti-inflammatory effect of heat shock protein induction is related to estabilization of IKB-á through preventing IkB kinase activation is respiratory epithelial cells. J Immunol. 2000;164:5416-20.

41. Wernerman J, Hammarqvist F. Modulation of endogenous glutathione availability. Curr Opin Clin Nutr Metab Care. 1999;2:487-92

42. Liboni KC, Li N, Scumpia PO, Neu J. Glutamine modulates LPS-induced IL-8 production through IKB/NFKB in human fetal and adult intestinal epithelium. J Nutr. 2005;135:245-51.

43. Klassen P, Mazariegos M, Solomons NW, Fürst P. The pharmacokinetic responses of human to $20 \mathrm{~g}$ of alanyl-glutamine dipeptide differ with the dosing protocol but not with gastric acidity or in patients with acute dengue fever. J Nutr. 2000;130:177-82.

44. Ziegler, TR. Glutamine supplementation in cancer patients receiving bone marrow transplantation and high dose chemotherapy. J Nutr. 2001;131: 25785-84S.

45. Shabert JK, Winslow C, Lacey JM, Wilmore DW. Glutamine-antioxidant supplementation increases body cell mass in aids patients with weight loss: a randomized, double-blind controlled trial. Nutrition. 1999;15:860-4

46. Fläring UB, Rooyackers OE, Wernerman J, Hammarqvist F. Glutamine attenuates post-traumatic glutathione depletion in human muscle. Clin Sci. 2003;104:275-82.

47. Valencia E, Marin A, Hardy G. Impact of L-glutamine on glutathione, glutamine and glutamate in blood levels in volunteers. Nutrition. 2002;18:367-70.

48. Déchelotte P, Darmaun D, Rongier M, Hecketsweiler B, Rigal O, Desjeux J. Absorption and metabolic effects of enterally administered glutamine in humans. Am J Physiol. 1991;260:G677-82.

49. Castell LM, Poortmans JR, Leclercq R, Brasseur M, Duchateau J, Newsholme EA. Some aspects of the acute phase response after a marathon race, and the effect of glutamine supplementation. Eur J Appl Physiol. 1997;75:47-53.

50. Bowtell JL, Gelly K, Jackman ML, Patel A, Simeoni M, Rennie MJ. Effect of oral glutamine on whole body carbohydrate storage during recovery from exhaustive exercise. J Appl Physiol. 1999;86:1770-7.

51. Castell LM, Newsholme EA. Glutamine and the effects of exhaustive exercise upon the immune response. Can J Physiol Pharmacol, 1998;76:524-32.

52. Castell LM, Newsholme EA. The effects of oral glutamine supplementation on athletes after prolonged exhaustive exercise. Nutrition. 1997;13:738-42.

53. Castell LM, Poortmans JR, Newsholme EA. Does glutamine have a role in reducing infections in athletes? Eur J Appl Physiol Occup Physiol. 1996;73:488-90.

54. Rohde T, Asp S, Maclean DA, Pederesen BK. Competitive sustained exercise in humans, lymphokine activated killer cell activity, and glutamine: an intervention study. Eur J Appl Physiol Occup Physiol. 1998;78:448-53.

55. Walsh NP, Blannin AK, Robson PJ, Gleeson M. Effect of oral glutamine supplementation on human neutrophil lipopolysaccharide-stimulated degranulation following prolonged exercise. Int J Sport Nutr Exerc Metab. 2000;10:39-50.

56. Krzywkowski K, Petersen EW, Ostrowski K, Kristensen JH, Boza J, Pedersen BK. Effect of glutamine supplementation on exerciseinduced changes in lymphocyte function. Am J Physiol Cell Physiol. 2001;281: C1259-65

57. Krzywkowski K, Petersen EW, Ostrowski K, Amster HL, Boza J, Kristensen JH, et al. Effect of glutamine and protein supplementation on exercise induced decreases in salivary lgA. J Appl Physiol. 2001;91:832-8.

58. Hiscock N, Petersen EW, Krzywkowski K, Boza J, Kristensen JH, Pedersen BK. Glutamine supplementation further enhances exercise-induced plasma IL-6. J Appl Physiol. 2003;95:145-8.

59. Ganapathy V, Brandsch M, Leibach FH. Intestinal transport of amino acid and peptides. In: Johson LR, Alpers DH, editors. The physiology of the gastrointestinal tract. New York: Raven Press, 1994. p. 1773-93.

60. Yang CY, Dantzig AH, Pidgeon C. Intestinal peptide transport systems and oral drug availability. Pharm Res. 1999;16:1331-43.

61. Vom Dahl S, Häussinger D. Nutritional state and the swelling-induced inhibition of proteolysis in perfused rat liver. J Nutr. 1996;126:395-402

62. Varnier M, Leese GP, Thompson J, Rennie MJ. Stimulatory effect of glutamine on glycogen accumulation in human skeletal muscle. Am J Physiol Endocrinol Metab. 1995;269:E309-15.

63. Rogero MM, Tirapegui JO, Pedrosa RG, Castro IA, Pires ISSO, Oliveira AAM, et al. Efeito da suplementação com L-alanil-L-glutamina sobre a resposta de hipersensibilidade do tipo tardio em ratos submetidos ao treinamento intenso. Rev Bras Cie Farm. 2002;38:487-97.

64. Rogero MM, Tirapegui JO, Pedrosa RG, Castro IA, Pires ISO. Effect of L-alanyl-L-glutamine supplementation on the plasma and tissue concentrations of glutamine in rats submitted to exhaustive exercise. Nutrition. 2006;22:564-71.

65. Rogero MM, Tirapegui JO, Pedrosa RG, Pires ISO, Castro IA. Plasma and tissue glutamine response to acute and chronic supplementation with L-glutamine and L-alanyl-L-glutamine in rats. Nutr Res. 2004:24:261-70. 